\title{
Early interventional treatment with intranasal corticosteroids is superior to post-onset treatment in Japanese cedar/cypress pollinosis
}

\author{
Takenori Haruna ${ }^{1 *}$, Mitsurhiro Okano ${ }^{2}$, Takaya Higaki ${ }^{2}$, Yasuyuki Noyama², Misato Hirai ${ }^{3}$, Kazunori Nishizaki ${ }^{2}$ \\ From 9th Symposium of Experimental Rhinology and Immunology of the Nose (SERIN 2013) \\ Leuven, Belgium. 21-23 March 2013
}

\section{Background}

The usefulness of early interventional treatment (EIT) with intranasal corticosteroids (INS) as compared to post-onset treatment (POT) has not been clarified. We sought to determine the efficacy and safety of EIT with INS compared with POT and placebo in Japanese cedar/cypress pollinosis.

\section{Method}

We designed a three-armed, double-blinded, randomized, placebo-controlled trial. Patients received mometasone furoate nasal spray (EIT group: $n=25)$, placebo $(n=25)$, or 4 weeks of placebo followed by 8 weeks of mometasone (POT group: $\mathrm{n}=25$ ) for a 12-week period starting on February 1,2011 . The primary endpoint was the comparison of the total nasal symptom score (TNSS) among the three groups. Total ocular symptom score (TOSS), total nasoocular symptom score (TSS), ARIA classification, safety, etc. were secondary endpoints.

\section{Results}

The placebo and POT groups, but not the EIT group, showed a significant exacerbation of TNSS and TOSS soon after the start of pollen counts being high on consecutive days. The 12-week average TSS in the EIT group (score, 2.3) was significantly lower than in the placebo (5.0; $\mathrm{P}<0.01)$ and $\mathrm{POT}(3.9 ; \mathrm{P}=0.03)$ groups. All subjects in the placebo and POT groups were classified as having persistent rhinitis, while $80 \%$ of the EIT group met the ARIA classification criteria $(\mathrm{P}=0.03)$. QOL score and nasal ECP levels were lower in the EIT and POT groups as compared with the placebo group. Daytime sleepiness,

'Okayama University Graduate School of Medicine, Dentistry and

Pharmaceutical Sciences, Okayama, Japan

Full list of author information is available at the end of the article smell disturbance and the average dose of loratadine taken as the rescue medication were similar. Treatment with mometasone was well tolerated.

\section{Conclusion}

EIT with INS is superior to POT in controlling pollinosis.

\section{Author details}

'Okayama University Graduate School of Medicine, Dentistry and Pharmaceutical Sciences, Okayama, Japan. ${ }^{2}$ Okayama University Graduate School of Medicine, Dentistry and Pharmaceutical Sciences, OtolaryngologyHead \& Neck Surgery, Okayama, Japan. ${ }^{3}$ Okayama Saiseikai General Hospital, Otolaryngology-Head \& Neck Surgery, Okayama, Japan.

Published: 16 July 2013

doi:10.1186/2045-7022-3-S2-P36

Cite this article as: Haruna et al:: Early interventional treatment with intranasal corticosteroids is superior to post-onset treatment in Japanese cedar/cypress pollinosis. Clinical and Translational Allergy 2013 3(Suppl 2):P36.

Submit your next manuscript to BioMed Central and take full advantage of:

- Convenient online submission

- Thorough peer review

- No space constraints or color figure charges

- Immediate publication on acceptance

- Inclusion in PubMed, CAS, Scopus and Google Scholar

- Research which is freely available for redistribution
C Biomed Central

( 2013 Haruna et al; licensee BioMed Central Ltd. This is an Open Access article distributed under the terms of the Creative Commons Attribution License (http://creativecommons.org/licenses/by/2.0), which permits unrestricted use, distribution, and reproduction in any medium, provided the original work is properly cited. 